\title{
NILAI PERUSAHAAN DITINJAU DARI TANGGUNG JAWAB SOSIAL, TATA KELOLA, DAN KESEMPATAN INVESTASI PERUSAHAAN Ni Nyoman Ayu Suryandari ${ }^{1}$, Frischa Faradilla Arwinda Mongan ${ }^{2}$ \\ ${ }^{1}$ Universitas Mahasaraswati Denpasar, ${ }^{2}$ Universitas Kristen Indonesia Paulus- Makassar \\ 1 ayusuryandari@unmas.ac.id
}

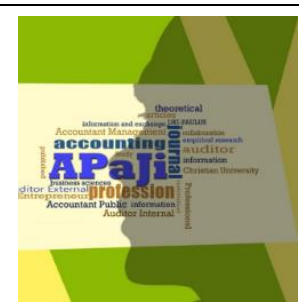

e-ISSN 2686-0058

p-ISSN 2715-7695

$\underline{\text { Informasi Artikel }}$

Tanggal masuk

09 Mei 2020

Tanggal revisi

25 Juni 2020

Tanggal diterima

23 Juli 2020

Kata Kunci: Company Value ${ }^{l}$ $C G P I^{2}$

Signal $^{3}$

Abstract: Firm value reflects the perception that investors give to the company. To increase company value, the company must provide information that can increase investor perceptions of the company. The signal that the company gives to investors in the form of financial reports will reduce information asymmetry so that investors are able to make quality decisions. Factors that are thought to influence firm value are social responsibility, corporate governance and corporate investment opportunities. By using a sample of 10 companies that participated in the 2016-2018 CGPI (Corporate Governance Perception Index), and by using multiple regression data analysis techniques, the results show that social responsibility and investment decisions are not factors that determine firm value, while improving corporate governance will reduce firm value.

Abstrak: Nilai perusahaan mencerminkan persepsi yang diberikan investor kepada perusahaan. Untuk meningkatkan nilai perusahaan maka perusahaan harus memberikan informasi yang mampu meningkatkan persepsi investor kepada perusahaan. Sinyal yang diberikan perusahaan kepada investor berupa laporan keuangan akan mengurangi asimetri informasi sehingga investor mampu mengambil keputusan yang bermutu. Faktor-faktor yang diduga berpengaruh terhadap nilai perusahaan adalah tanggung jawab sosial, tata kelola perusahaan dan kesempatan investasi perusahaan. Dengan menggunakan sampel 10 perusahaan yang mengikuti CGPI (Corporate Governance Perception Index) tahun 2016-2018, dan dengan menggunakan. Teknik analisis data multiple regression maka diperoleh hasil bahwa tanggung jawan sosial dan keputusan investasi bukanlah faktor yang menentukan nilai perusahaan, sementara peningkatan tata kelola perusahaan akan mengurangi nilai perusahaan.
\end{abstract}

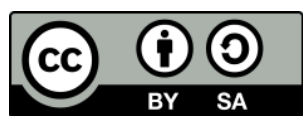

\section{PENDAHULUAN}

Peningkatan nilai perusahaan menjadi tujuan jangka Panjang entitas bisnis (Shintawati 2011). Persepsi investor atas suatu perusahaan tercermin dari harga saham perusahaan yang nantinya akan menentukan tinggi rendahnya nilai perusahaan. Tantangan perusahaan adalah untuk menarik hati para investor dengan adanya persaingan global yang ketat sehingga perusahaan harus meningkatkan daya saing perusahaan. Nilai perusahaan juga diartikan sebagai besarnya nilai jual perusahaan atau besarnya nilai atas pertumbuhan pemegang saham. Hal ini karena harga saham akan mencerminkan penilaian investor terhadap kinerja perusahaan (Sapsepti 2017). Dengan pentingnya nilai perusahaan maka perusahaan wajib melakukan 
tindakan yang mampu mempertahankan atau meningkatkan nilai perusahaan. Beberapa hal yang diperhatikan perusahaan diantaranya adalah tanggung jawab sosial, tata kelola perusahaan dan focus pada kesempatan investasi perusahaan (Permatasari 2010; Kusumadilaga 2010; Retno 2012; dan Sinthawati 2011).

Dengan melaksanakan tanggung jawab sosial kepada masyarakat maka perusahaan lebih dikenal masyarakat sehingga meningkatkan citra perusahaan dan meningkatkan loyalitas masyarakat untuk mengkonsumsi produk/ jasa perusahaan. Hal ini didasarkan atas fokus perusahaan bukan lagi pada single bottom line namun mengarah pada triple bottom lines yaitu finansial, sosial dan lingkungan karena ketiganya mampu meningkatkan nilai perusahaan secara berkelanjutan.

Selain tanggung jawab sosial, investor juga kerap mempertimbangkan tata kelola perusahaan dalam melakukan penilaian terhadap perusahaan (Subekti 2013). Adanya tata kelola perusahaan akan dapat meminimalkan konflik agensi antara agent dan principle. Konflik tersebut harus segera diatasi oleh perusahaan agar tidak merugikan salah satu pihak karena masing-masing pihak memiliki kepentingan yang berbeda. Masing-masing pihak harus dilindungi kepentingannya dengan penerapan tata kelola perusahaan (Retno 2012). Tata kelola perusahaan dapat menurunkan kerugian akibat adanya pengawasan (monitoring) dan pelaksanaan perusahaan yang lebih terstruktur (Wulandari 2013). Penerapan tata kelola perusahaan di perusahaan publik diharapkan dapat mengembalikan kepercayaan masyarakat. Selain itu, penerapan tata kelola perusahaan tersebut juga dimaksudkan untuk mengantisipasi persaingan yang ketat di era ini.

Adanya kasus pada PT Jasa Marga merupakan salah satu contoh akibat lemahnya tata kelola perusahaan. Dalam kasus ini manajer memberikan gratifikasi kepada auditor BPK berupa motor Harley Davidson. Kasus ini menyebabkan merosotnya harga saham PT Jasa Marga hingga level Rp. 5.600 per lembar sahamnya (www.koran-jakarta.com). Adanya CGPI (Corporate Governance Perception Index) di Indonesia berperan dalam peningkatan kualitas tata kelola perusahaan sehingga skor ini nantinya mampu meningkatkan kepercayaan stakeholder kepada perusahaan. Peningkatan nilai perusahaan juga ditentukan oleh kesempatan investasi yang dilaukan perusahaan yang terkait dengan pilihan investasi perusahaan yang mampu menghasilkan NPV (Net Present Value) yang positif.

Berdasarkan fenomena yang terjadi maka penelitian ini mencoba menguji pengaruh tanggung jawab sosial, tata kelola perusahaan dan kesempatan investasi pada nilai perusahaan dengan menggunakan perusahaan yang masuk dalam CGPI (Corporate Governance Perception Index) tahun 2016-2018) sebagai sampel.

\section{TINJAUAN PUSTAKA}

Penelitian terkiat nilai perusahaan didasarkan pada teori signaling. Teori ini menjelaskan alas an perusahaan beruaha memberikan informasi laporan keuangan kepada stakeholder, yaitu karena adanya informasi yang tidak simetris (asimetri informasi). Perusahaan memiliki informasi yang jauh lebih kompleks dibandingkan informasi yang disampaikan kepada pihak luar. Investor yang memiliki informasi yang terbatas akan bersifat pesimis sehingga memberikan harga pada tingkat rendah. Hal ini dapat diantisipasi oleh perusahaan dengan cara mengurangi terjadinya asimetri informasi dengan memberikan lebih banyak signal kepada investor seperti informasi terkait laporan keuangan. Investor yang 
memperoleh informasi akan menganalisis sesuai dengan kecanggihan investor. Apakah informasi tersebut merupakan good news atau bad news. Good news yang diterima oleh investor akan berdampak pada kenaikan harga saham (sehingga terjadi peningkatan nilai perusahaan) karena investor berasumsi perusahaan memiliki prospek usaha yang baik sementara jika investor menganggap informasi tersebut tergolong bad news maka berdampak pada penurunan harga saham (sehingga terjadi penurunan nilai perusahaan) karena investor berasumsi prospek perusahaan kurang menguntungkan.

\section{Gambar 1. Kerangka Berpikir}

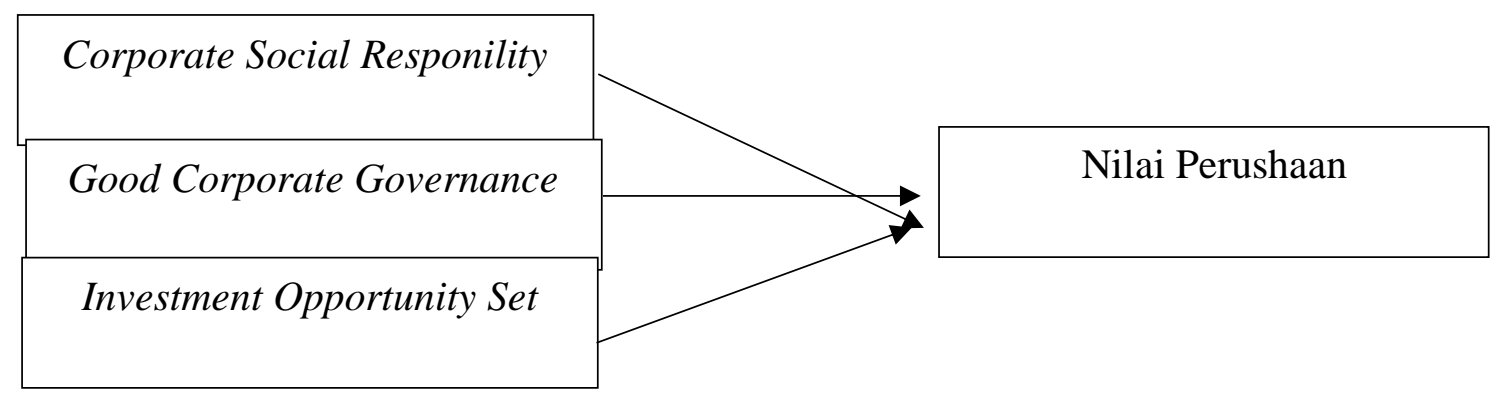

\section{Pengaruh Tanggung Jawab Sosial Terhadap Nilai Perusahaan}

Perusahaan menyajikan informasi terkait tanggung jawab sosial pada laporan keberlanjutan (sustainable reporting) (Kusumadilaga 2010). Perusahaan harus melaksanakan tanggung jawab sosial perusahaan secara berkelanjutan dengan penuh komitmen bersama dengan para karyawannya agar program tersebut bukan hanya untuk formalitas belaka. Program sosial akan memberikan arti tersendiri bagi perusahaan jika program tersebutdilaksanakan dengan sungguh-sungguh.

Perusahaan dapat menjaga sustainabilitynya jika mampu menyelaraskan aspek ekonomi, sosial dan lingkungan. Dengan adanya keberlanjutan tersebut akan menjamin peningkatan dalam nilai perusahaan. Pelaksanaan tanggung jawab sosial merupakan bentuk keperdulian perusahaan terhadap lingkungan sekitar. Dengan melaksanakan tanggung jawab sosial akan meningkatkan reputasi dan citra perusahaan dimata masyarakat atau investor sehingga berdampak pada nilai perusahaan. Berdasarkan uraian diatas maka dugaan awal dalam penelitian ini adalah:

$\mathrm{H}_{1}$ : Tanggung jawab sosial meningkatkan nilai perusahaan.

\section{Pengaruh Tata Kelola Perusahaan Terhadap Nilai Perusahaan}

Tata kelola perusahaan merupakan system atau aturan yang berusaha melakukan pengaturan, pengelolaan dan pengawasan hubungan perusahaan dengan stakeholder. Penerapan tata kelola perusahaan yang baik dalam perusahaan mampu meningkatkan nilai perusahaan. Tata kelola perusahaan yang baik dapat mengawasi agency cost. Hasil penelitian Retno (2012) menyatakan tata kelola perusahaan berpengaruh positif terhadap nilai perusahaan sehingga dugaan awal dalam penelitian ini adalah:

$\mathrm{H}_{2}$ : Tata kelola perusahaan meningkatkan nilai perusahaan.

\section{Pengaruh Kesempatan Investasi Terhadap Nilai Perusahaan}

Kesempatan investasi perusahaan berperan penting karena berkaitan dengan keputusan investasi perusahaan dalam kaitannya dalam menentukan kombinasi aktiva perusahaan dan pilihan perusahaan dalam berinvestasi pada masa mendatang. Perusahaan akan memilih 
berinvestasi pada pada proyek yang menghasilkan NPV (Net Present Value) yangbernilai positif. Sesuai dengan hasil penelitian Sinthawati (2011) dan Astriani (2014) bahwa set kesempatan investasi berpengaruh positif terhadap nilai perusahaan maka dugaan awal penelitian ini adalah:

$\mathrm{H}_{3}$ : Kesempatan investasi perusahaan mampu meningkatkan nilai peruahaan.

\section{METODE PENELITIAN}

Penelitian ini mengambil lokasi pada perusahaan yang terdaftar di IDx dengan mengkaji variable yang mempengaruhi nilai perusahaan yaitu tanggung jawab sosial, tata kelola dan kesempatan investasi perusahaan.

Tabel 1. Definisi operasional variable

\begin{tabular}{|l|l|l|}
\hline \multicolumn{1}{|c|}{ Nama Variabel } & \multicolumn{1}{|c|}{ Pengertian } & \multicolumn{1}{|c|}{ Indikator } \\
\hline Tanggung Jawab Sosial & $\begin{array}{l}\text { Pengintegrasian operasi } \\
\text { perusahaan dengan } \\
\text { lingkungan dan sosial terkait } \\
\text { kebutuhan stakeholder } \\
\text { (Anggraini 2006). }\end{array}$ & GRI dengan 84 indikator \\
\hline Tata Kelola Perusahaan & $\begin{array}{l}\text { Sistem yang mengatur } \\
\text { hubungan antara perusahaan } \\
\text { dengan stakeholder }\end{array}$ & $\begin{array}{l}\text { Nilai CGPI 2016-2018 } \\
\text { Perusahaan }\end{array}$ \\
\hline Investasi & $\begin{array}{l}\text { Pilihan investasi yang } \\
\text { diharapkan menghasilkan } \\
\text { return yang } \\
\text { besar (Hasnawati 2005) }\end{array}$ & $\begin{array}{l}\text { Capital Expenditure to Book } \\
\text { Value of Assets Ratio } \\
\text { (CAP/BVA) }\end{array}$ \\
\hline Nilai Perusahaan & $\begin{array}{l}\text { Nilai jual } \\
\text { perusahaan atau nilai tumbuh } \\
\text { bagi pemegang saham } \\
\text { (Febrina 2010) }\end{array}$ & $\begin{array}{l}\text { Q Ratio, nilai Q ratio diatas 1 } \\
\text { (satu) } \\
\text { perusahaan menandakan } \\
\text { prospek pertumbuhan yang } \\
\text { baik }\end{array}$ \\
\hline
\end{tabular}

Perusahaan yang mengikuti pemeringkatan CGPI berturut-turut dari tahun 2016-2018 menjadi populasi dalam penelitian ini dengan total sebanyak 49 perusahaan. Dengan menggunakan purposive sampling, diperoleh 10 (sepuluh) perusahaan yang masuk kriteria sampel. 
Tabel 2. Kriteria Penentuan Sampel

\begin{tabular}{|c|l|c|}
\hline No. & \multicolumn{1}{|c|}{ Kriteria } & $\begin{array}{l}\text { Jumlah Pengamatan } \\
\text { Perusahaan Sampel }\end{array}$ \\
\hline 1 & $\begin{array}{l}\text { Perusahaan yang tercatat di CGPI Award Tahun 2016-2018 dan } \\
\text { memperoleh skor kategori sangat terpercaya, terpercaya, dan cukup } \\
\text { terpercaya }\end{array}$ & 19 \\
\hline 2 & Perusahaan yang tidak termasuk peringkat CGPI 2016-2018 & $(9)$ \\
\hline 3 & Perusahaan tidak ditemukan laporan keuangan Tahun 2015-2018 & $(0)$ \\
\hline 4 & Data tidak lengkap & 10 \\
\hline & Total Sampel & 30 \\
\hline
\end{tabular}

Sumber : Majalah SWA, Data Diolah 2019

Teknik analisis data yang digunakan adalah multiple regression yang sebelumnya memerlukan uji asumsi klasik sebagai syarat pengujian multiple regression.

\section{Uji Asumsi Klasik}

Uji ini digunakan untuk menilai kelayakan model multiple regression yang meliputi:

1) Uji Normalitas

Pengujian normalitas menggunakan nilai Kolmogorov-Smirnov dengan pedoman nilai signifikansi melebihi 0,05 (Ghozali 2016: 103).

2) Uji Multikolinieritas

Pengujian ini menilai korelasi antara satu variable bebas dengan variable bebas yang lainnya (Ghozali 2016:103). Nilai tolerance harus di atas 10\% dan nilai VIF harus di bawah 10 agar model regresi tidak mengandung multikolinieritas.

3) Uji Autokorelasi

Pengujian ini dapat menilai apakah terdapat hubungan antara data $\mathrm{t}-1$ dengan data periode $\mathrm{t}$ dengan menggunakan uji DurbinWatson.

4) Uji Heteroskedastisitas

Pengujian ini dimaksudkan untuk menilai ketidaksamaan varians dari model regresi (Ghozali 2016:134) dengan menggunakan uji glejser dengan pedoman tingkat signifikansi melebihi 0,05, agar tidak terjadi heteroskedastisitas.

\section{Analisis Multiple Regression}

Untuk mengetahui arah dan pengaruh variable tanggung jawab sosial, tata kelola perusahaan dan kesempatan investasi terhadap nilai perusahaan, digunakan analisis multiple regression dengan persamaan sebagai berikut:

$\mathrm{NP}=\alpha+\beta_{1} \mathrm{TJS}+\beta_{2} \mathrm{TKP}+\beta_{3} \mathrm{KIP}+\mathrm{e}$

Keterangan :

$\mathrm{NP}=$ Nilai perusahaan

TJS = Tanggung Jawab Sosial 
TKP = Tata Kelola Perusahaan

KIP = Kesempatan Investasi Perusahaan

\section{Uji Koefisien Determinasi (Adjusted $\mathbf{R}^{\mathbf{2}}$ )}

Penelitian ini memilih menggunakan nilai adjusted $\mathrm{R}^{2}$ dibandingkan dengan nilai $\mathrm{R}^{2}$ dengan alasan bahwa jika digunakan adjusted $\mathrm{R}^{2}$, penambahan satu variable bebas belum tentu akan langsng meningkatkan nilai adjusted $\mathrm{R}^{2}$ sementara jika digunakan $\mathrm{R}^{2}$, penambahan satu variable bebas akan menaikkan nilai $\mathrm{R}^{2}$.

\section{Uji Regresi Simultan (Uji F)}

Uji $\mathrm{F}$ menilai kesesuaian data amatan dengan model regresi dengan menggunakan pedoman signifikan sebesar 5\%.

\section{Uji Parsial (Uji t)}

Uji t digunakan untuk menilai signifikansi variabel independen terhadap variabel dependennya secara parsial dengan menggunakan pedoman signifikansi sebesar $5 \%$.

\section{HASIL DAN PEMBAHASAN}

Statistik Deskriptif

Tabel 3. Statistik Deskriptif

\begin{tabular}{llllll}
\hline Variabel & $\mathrm{N}$ & Minimum & Maksimum & Rata-rata & Standar Deviasi \\
\hline TJS & 30 & 0.10 & 0.61 & 0.2722 & 0.12766 \\
TKP & 30 & 72.68 & 93.86 & 86.2077 & 5.16723 \\
KIP & 30 & -0.01 & 0.18 & 0.147 & 0.03374 \\
NP & 30 & 0.88 & 2.64 & 1.2719 & 0.48371 \\
\hline
\end{tabular}

1) Variabel tanggung jawab sosial (TJS) dengan nilai terendah 0,10 pada PT. Bakrie \& Brother, Tbk tahun 2016 dan tertinggi sebesar 0,61 pada PT. Timah (Persero), Tbk tahun 2016-2018 dimana secara rata-rata bernilai 0,2772 dan tingkat deviasi 0,12766 yang dapat disimpulkan data amatan untuk variable tanggung jawab sosial memiliki nilai standar deviasi yang mendekati nol atau cenderung homogen.

2) Variabel tata kelola perusahaan (TKP) dengan nilai terendah 72,68 , nilai tertinggi 93,86 dan secara rata-rata adalah 86,2077 , hal ini menunjukkan sebagian besar rata-rata nilai tata kelola perusahaan cukup tinggi, dan standar deviasi 5,16723 yang berarti data untuk variabel tata kelola perusahaan terjadi penyimpangan nilai tata kelola perusahaan terhadap nilai rata-rata 5,16723.

3) Variabel Kesempatan Investasi memiliki nilai terendah -0,01, nilai tertinggi 0,18 dengan rata-rata 0,0147 , standar deviasi 0,03374 yang dapat disimpulkan data amatan untuk variable kesempatan investasi memiliki nilai standar deviasi yang mendekati nol atau cenderung homogen.

4) Variabel nilai perusahaan memiliki nilai terendah 0,88 , nilai tertinggi 2,64 dengan ratarata 1,2719 , standar deviasi 0,48371 yang berarti data untuk nilai perusahaan terjadi penyimpangan nilai perusahaan terhadap nilai rata-rata 0,48371 . 


\section{Pengujian Asumsi Klasik}

1) Uji Normalitas

Hasil uji Kolomogorov-Smirnov dapat dilihat pada tabel 4 yaitu sebagai berikut:

Tabel 4. Uji Kolmogorov-Smirnov

\begin{tabular}{ccc}
\hline $\mathrm{N}$ & & 30 \\
\hline Normal Parameters & Mean & 0.000000 \\
& Std. Deviation & 0.38772737 \\
Most Extreme & Absolute & 0.149 \\
Differences & & \\
& Positive & 0.146 \\
Test Statistic & Negative & -0.149 \\
Asymp. Sig (2 Tailed) & & 0.149 \\
\hline
\end{tabular}

Berdasarkan Tabel 4, nilai Kolmogorov-Smirnov (K-S) sebesar 0,149, dengan nilai signifikansi 0,089 sehingga distribusi data normal.

2) Uji Multikolinearitas

Adapun hasil uji multikolinearitas disajikan pada Tabel 5:

Tabel 5. Uji Multikolinearitas

\begin{tabular}{lcr}
\hline \multirow{2}{*}{ Variabel } & \multicolumn{3}{c}{ Collinearity Statistics } \\
\cline { 2 - 3 } CSR & Tolerance & VIF \\
GCG & .990 & 1.010 \\
IOS & .999 & 1.001 \\
& .989 & 1.011
\end{tabular}

Berdasarkan Tabel 5 nilai tolerance dan VIF dari variabel tanggung jawab sosial, tata kelola perusahaan dan kesempatan investasi menunjukkan nilai lebih besar dari 0,100 dan nilai VIF lebih kecil dari 10 berarti tidak terdapat multikolinearitas.

\section{3) Uji Autokorelasi}

Hasil Uji Durbin Watson ditunjukan pada tabel 6:

Tabel 6. Uji Autokorelasi

\begin{tabular}{cccccc}
\hline Model & $\mathrm{R}$ & R square & $\begin{array}{c}\text { Adjusted R } \\
\text { square }\end{array}$ & $\begin{array}{c}\text { Std. Error of } \\
\text { the estimate }\end{array}$ & $\begin{array}{c}\text { Durbin } \\
\text { watson }\end{array}$ \\
\hline 1 & 0.598 & 0.357 & 0.283 & 0.40949 & 1.856 \\
\hline
\end{tabular}

Nilai $\mathrm{d}_{\mathrm{u}}$ adalah 1,6498 sehingga nilai Durbin-Watson pada penelitian ini yaitu $1,6498<1,856<2,3502$ maka tidak terjadi gejala autokorelasi. 


\section{4) Uji Heteroskedatisitas}

Tabel 7. Uji Hesteroskedastisitas

\begin{tabular}{ccccc}
\hline Model & & $\mathrm{B}$ & $\mathrm{t}$ & Sig \\
\hline 1 & (Constant) & -63.942 & -1.224 & 0.232 \\
& TJS & -5.843 & -0.239 & 0.813 \\
& TKP & 0.794 & 1.320 & 0.198 \\
& KIP & 25.018 & 0.270 & 0.789
\end{tabular}

Dari tabel 7 nilai signifikansi setiap variabel bebas tidak signifikan sehingga tidak terjadi gejala heteroskedastisitas.

\section{Koefisien Determinasi (Adjusted $\mathbf{R}^{\mathbf{2}}$ )}

Berdasarkan Tabel 6 nilai Adjusted $R$ Square sebesar 0,283 artinya variabel bebas yaitu tanggung jawab sosial, tata kelola perusahaan dan kesempatan investasi menjelaskan variabel terikat yaitu nilai perusahaan sebesar 28,3 persen sedangkan sisanya 71,7 persen dijelaskan oleh variable lain.

\section{Uji Kelayakan Model (Uji F)}

Nilai signifikansi uji F sebesar 0,008 sehingga secara simultan berpengaruh terhadap nilai perusahaan atau model fit dengan data observasinya.

\section{Uji Parsial (Uji t)}

1. Pengaruh tanggung jawab sosial pada nilai perusahaan.

Tanggung jawab sosial memiliki nilai signifikansi sebesar 0,058 yang berarti tanggung jawab sosial tidak mempengaruhi nilai perusahaan yang sejalan dengan hasil riset Hersiana (2017), Nurhayati (2012). Hal ini tidak sesuai dengan dugaan awal dalam penelitian ini yakni tanggung jawab sosial akan meningkatkan nilai perusahaan. Terjadinya peningkatan nilai tanggung jawab sosial perusahaan tidak memberikan dampak pada harga saham. Investor umumnya berfokus pada return berupa capital gain atau dividen tanpa berfokus oada tanggung jawab sosial perusahaan, bentuk-bentuk tanggung jawab sosial perusahaan tidak dapat secara langsung atau dalam jangka waktu yang singkat oleh masyarakat karena tanggung jawab sosial perusahaan merupakan strategi jangka Panjang untuk kesejahteraan masyarakat.

2. Pengaruh tata kelola perusahaan pada nilai perusahaan

Tata kelola perusahaan memiliki nilai signifikansi sebesar 0,004 dengan koefisien 0,046 yaitu peningkatan tata kelola perusahaan malah mampu menurunkan nilai perusahaan. Hal ini tidak mendukung dugaan awal penelitian bahwa dengan tata kelola perusahaan maka akan meningkatkan nilai perusahaan. Hal ini mungkin terjadi karena belum optimalnya implementasi tata kelola perusahaan yang dilaksanakan atau karena belum optimalnya implementasi tata kelola perusahaan yang dilaksanakan atau karena implementasi tata kelola perusahaan hanya sekedar formalitas saja sesuai dengan yang diwajibkan oleh aturan pemerintah.

3. Pengaruh kesempatan investasi pada nilai perusahaan

Variable kesempatan investasi memiliki nilai signifikansi 0,685 sehingga variabel keputusan investasi perusahaan tidak mampu mempengaruhi nilai perusahaan. Hal ini sesuai dengan hasil riset Rahmayani dan Silvana (2018). Beberapa hal yang mungkin menyebabkan hal tersebut adalah keputusan investasi yang dilakukan oleh perusahaan 
kurang tepat. Selain itu, variabel ini menggunakan rasio CAP/ BVA dengan membandingkan asset periode sekarang dengan periode sebelumnya. Terjadinya penurunan asset periode sekarang, bukan berarti asset periode berikutnya juga mengalami penurunan.

\section{PENUTUP}

\section{Simpulan}

Berdasarkan pada teori signaling, laporan keuangan memberikan informasi yang bermanfaat bagi investor dalam pengambilan keputusan. Hal ini akan mempengaruhi nilai perusahaan yang tercermin dari harga saham perusahaan. Sehingga perlu dikaji faktor-faktor yang mempengaruhi naik turunnya nilai perusahaan. Penelitian ini berhasil membuktikan bahwa tanggung jawab sosial dan keputusan investasi bukanlah factor yang mempengaruhi nilai perusahaan, sementara peningkatan tata kelola perusahaan mampu menurunkan nilai perusahaan.

\section{Saran}

1. Sampel dalam penelitian ini relative kecil karena rendahnya perusahaan yang terdaftar berturut-turut pada pemeringkatan CGPI, penelitian berikutnya dapat menggunakan mekanisme GCG sebagai proksi dari tata kelola perusahaan sehingga menghasilkan sampel lebih banyak.

2. Menggunakan indicator GRI dengan 91 item pengungkapan

3. Rendahnya nilai adjusted R2 dalam penelitian ini sehingga peneliti berikutnya dapat menggunakan variabel lain yang dianggap mempengaruhi nilai perusahaan.

\section{DAFTAR PUSTAKA}

Anggraini, F. R. R. (2006). Pengungkapan informasi sosial dan faktor-faktor yang mempengaruhi pengungkapan informasi sosial dalam laporan keuangan tahunan (Studi empiris pada perusahaan-perusahaan yang terdaftar Bursa Efek Jakarta). Simposium Nasional Akuntansi, 9, 23-26.

Astriani, E. F. (2014). Pengaruh kepemilikan manajerial, leverage, profitabilitas, ukuran perusahaan dan investment opportunity set terhadap nilai perusahaan. Jurnal Akuntansi, 2(1).

Febrina, N. (2010). Pengaruh Komisaris Independen Dan Kinerja Keuangan Terhadap Nilai Perusahaan (Studi Empiris Pada Perusahaan Wholesale Yang Terdaftar Di Bursa Efek Indonesia). Jurnal Jurusan Manajemen, Fakultas Ekonomi-Universitas Gunadarma, 10206676.

Ghozali, I. (2016). Aplikasi Analisis Multivariete IBM SPSS 23. Badan Penerbit Universitas Diponegoro, Semarang.

Hasnawati, S. (2005). Dampak set peluang investasi terhadap nilai perusahaan publik di Bursa Efek Jakarta. Jurnal Akuntansi dan Auditing Indonesia, 9(2).

Hersiana, M. A. (2017). Pengaruh corporate social responsibility terhadap nilai perusahaan dengan corporate governance sebagai variabel moderasi (Doctoral dissertation, Widya Mandala Catholic University Surabaya).

Kusumadilaga, R. (2010). Pengaruh corporate social responsibility terhadap nilai perusahaan dengan profitabilitas sebagai variabel moderating (Studi empiris pada perusahaan 
manufaktur yang terdaftar di Bursa Efek Indonesia) (Doctoral dissertation, Perpustakaan FE UNDIP).

Nurhayati, M. (2012). Analisis Pengaruh Kinerja Keuangan, Good Corporate Governance Dan Corporate Social Responsibility Terhadap Nilai Perusahaan Yang Terdaftar Dalam LQ45 pada Tahun 2009-2011.

Permatasari, V. D. (2010). Praktik intellectual capital disclosure dan permintaan narrow financial based stakeholders di Indonesia.

Rahmayani, R., \& Silvana, H. (2018). Program Corporate Social Responsibility (CSR) Pada PT Indocement Tunggal Prakarsa Tbk. PRofesi Humas, 2(2), 186-202.

Retno, R. D., \& Priantinah, D. (2012). Pengaruh good corporate governance dan pengungkapan corporate social responsibility terhadap nilai perusahaan (studi empiris pada perusahaan yang terdaftar di Bursa Efek Indonesia periode 2007-2010). Nominal: Barometer Riset Akuntansi dan Manajemen, 1(2), 99-103.

SAPSEPTI, G. (2017). PENGARUH PROFITABILITAS, GOOD CORPORATE GOVERNANCE TERHADAP NILAI PERUSAHAAN (Studi Kasus Pada Perusahaan Peserta CGPI (Corporate Governance Perception Index) Yang Terdaftar Di Bursa Efek Indonesia Periode 2011-2014) (Doctoral dissertation, Fakultas Ekonomi dan Bisnis Unpas Bandung).

Shintawati, V. R. (2011). Pengaruh Board Diversity, Investment Opportunity Set (IOS), dan Kinerja Keuangan terhadap Nilai Perusahaan yang Terdaftar di Bursa Efek Indonesia Tahun 2008.

Subekti, I. (2013). Accrual and Real Earnings Management: One of The Perspectives of Prospect Theory. Journal of Economics, Business, \& Accountancy Ventura, 15(3), 443456.

Wulandari, D. R. (2013). Pengaruh Profitabilitas, Operating Leverage, Likuiditas terhadap nilai perusahaan dengan struktur modal sebagai intervening. Accounting Analysis Journal, 2(4). 